oc.

101.60/2:

824

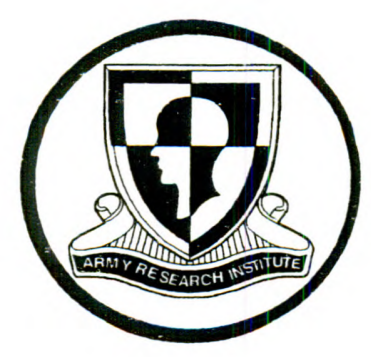

\author{
U.S. Army Research Institute \\ for the Behavioral and Social Sciences
}

Research Report 1824

\title{
Assessment of the Think Like a Commander Training Program
}

Scott B. Shadrick and James W. Lussier U.S. Army Research Institute

July 2004

US Govt. Document

Doc Ex

DEC 012004

University of Illinois At Urbana-Champast

Approved for public release; distribution is unlimited. 